\title{
LIPOMA OF CAECUM CAUSING ILEO-COLOCOLIC INTUSSUSCEPTION- A CASE REPORT
}

\author{
Gaurav Wadhawan ${ }^{1}$ Kailash Chandra Vyas $^{2}$
}

${ }_{1}^{1}$ Associate Professor, Department of General Surgery, Pacific Medical College and Hospital, Udaipur, Rajasthan, India. 2Professor and HOD, Department of General Surgery, Pacific Medical College and Hospital, Udaipur, Rajasthan, India.

HOW TO CITE THIS ARTICLE: Wadhawan G, Vyas KC. Lipoma of caecum causing ileo-colocolic intussusception- a case report. J. Evolution Med. Dent. Sci. 2018;7(31):3563-3564, DOI: 10.14260/jemds/2018/800

\section{PRESENTATION OF CASE}

A 28 years old male got admitted in the emergency with history of pain abdomen from last seven days with nausea and vomiting. On examination, there was a vague tender sausage shaped mass palpable in the right upper quadrant. He was investigated, and his ultrasound and CT scan revealed ileo-colocolic intussusception with a well-defined lipoma measuring $4.4 \mathrm{~cm} \times 4.5 \mathrm{~cm}$ in caecum acting as a lead point. The length of the intussusception segment was about $16 \mathrm{cms}$. The mesentery and its vessels were also invaginated. There were mildly enlarged mesenteric lymph nodes adjacent to the intussusception with mild ascites. CT also showed cholelithiasis.

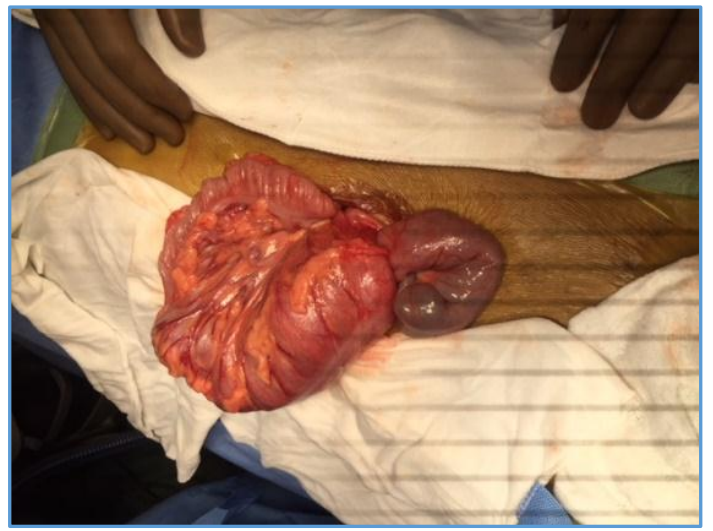

Figure 1. Ileocolocolic Intussusception

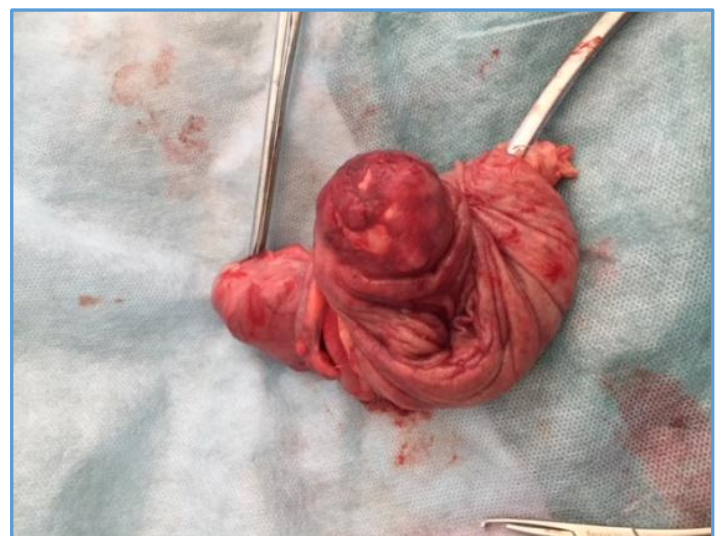

Figure 2. Polypoid Caecal Mass-Lead Point

'Financial or Other Competing Interest': None.

Submission 20-06-2018, Peer Review 13-07-2018,

Acceptance 20-07-2018, Published 30-07-2018.

Corresponding Author:

Dr. Gaurav Wadhawan

\#3, Dhabai Complex,

N. B. Nagar, Bedwas,

Udaipur-313024

Rajasthan, India.

E-mail: gauravwadhawan9@gmail.com

DOI: $10.14260 /$ jemds $/ 2018 / 800$

\section{(c) $(1) \$$}

Patient was operated with a right paramedian incision. There was an ileo-colocolic intussusception present in the right upper quadrant with a lump of about $16 \mathrm{cms}$ length in transverse colon. The caecum, appendix, ileum and ascending colon were telescoped into the transverse colon (Fig. 1). The intussusceptum segment was manually reduced from the transverse colon which was the intussuscipiens segment. There was a polypoid mass in caecum which acted as the lead point (Fig. 2), appendix was not inflamed, and few mesenteric lymph nodes were enlarged. About $12 \mathrm{~cm}$ of intestine from terminal ileum to half of proximal ascending colon was excised and end-to-end ileo ascending colon anastomosis was done, mesenteric lymph node was also taken for histopathology along with the excised segment. The histology report showed submucosal lipoma (Fig. 3) with reactive lymphadenitis. The post-operative period was uneventful, and patient was discharged satisfactorily.

Intussusception, telescoping of one segment of bowel into adjacent one, usually the proximal into the distal, is commonly described in infants and children from age group 6 months to 3 years. In adults, intussusception is estimated to account for only $5 \%$ and causes $1 \%$ of all bowel obstruction and $0.003-0.02 \%$ of all hospital admissions. ${ }^{[1]}$

Almost, $90 \%$ of cases of adult intussusception have underlying bowel pathology such as carcinoma, polyps, Meckel's diverticulum, benign neoplasms, endometriosis, Crohn's disease, colonic diverticulum or adhesions which are discovered intraoperatively. [2] However, neoplasm is the most common cause and is found in approx. $65 \%$ of adult cases. ${ }^{[3]}$ Benign tumours of the intestine arise either from the epithelium or from connective tissue. Lipoma is the second most common benign tumour of the intestine after adenomas. They are usually sessile and located in the submucosa of bowel. The right colon is mostly affected. In $20 \%$ of patients the tumour is the lead point of intussusception. ${ }^{[4]}$ The present case describes a case of ileo-colocolic intussusception due to a big submucosal lipoma of the caecum as the lead point.

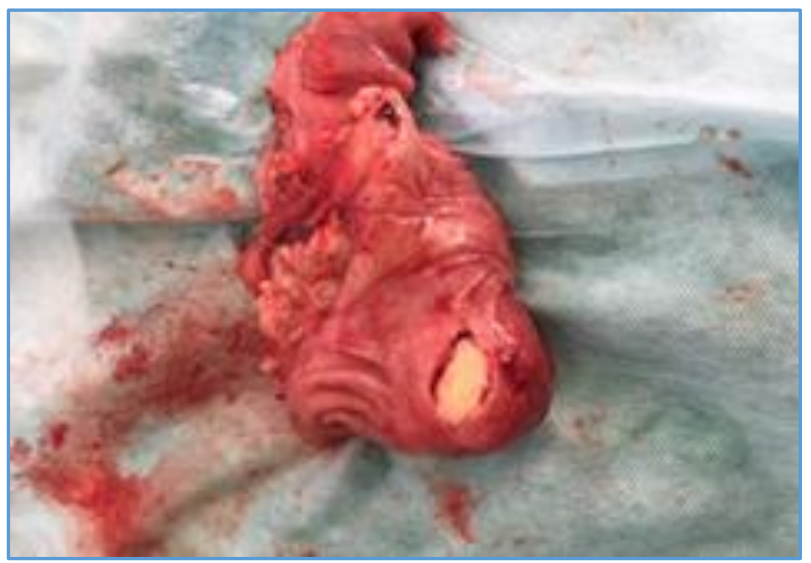

Figure 3. Submucosal Lipoma of Caecum 


\section{DIFFERENTIAL DIAGNOSIS}

The case presented with pain abdomen, nausea, vomiting and a lump in the right upper quadrant mimicking differential diagnosis of an appendicular lump, gall bladder phlegmon or malignancy, hepatic cyst, abscess or mass, pyloric stenosis or malignancy, malignancy of hepatic flexure or transverse colon, gastric volvulus or gastroenteritis, internal hernias or GIST.

\section{CLINICAL DIAGNOSIS}

The presence of a sausage shaped lump in the right upper quadrant and empty right iliac fossa and the ultrasound picture of target sign along with confirmatory proof revealed via CT scan, helped us to come to a diagnosis and we proceeded for the laparotomy. There was a big telescoped segment of ileum with appendix and proximal colon into transverse colon forming a lump. This was the ileo-colocolic intussusception.

\section{PATHOLOGICAL DISCUSSION}

Intussusception was first described in 1674 by Barbette of Amsterdam.[5] It is a rare cause of intestinal obstruction in adults. In children intussusception is usually idiopathic or secondary to viral illness, usually seen after the weaning period, but in adults in more than $90 \%$ of cases a lead point can be identified causing the intussusception and the majority of these may be colonic malignant tumours, polyp or benign tumours and inverted Meckel's diverticulum. The incidence of intussusception a characteristic complication of submucosal lipoma of the large bowel is $40-50 \%$. These tumours become polypoid and pushed forward as a result of peristaltic action. Most of them are sessile, but a few develop stalks. These tumours are composed of lobulated masses of highly vascular adult fat cells. These tumours do not tend to undergo malignancy.

Intussusception due to endometriosis[6] and neurofibroma has also been reported in adults. Stubenbord and Thorbjarnarson[7] reported 34 cases of intussusception, 25 affecting the small bowel and 9 affecting the large bowel, 9 had no obvious cause and 16 had benign tumours. Stetten[8] described a masterly review of 77 cases of submucosal lipoma of the intestinal tract.

Intussusception is a common cause of bowel obstruction in infants, in whom it presents with classical triad of symptoms and sign: Crampy abdominal pain, a palpable sausage shaped mass, mainly in the right quadrant and currant jelly stools.[9] On the contrary, adult intussusception presents with a wide range of symptoms, often with a colicky pain and intermittent partial intestinal obstruction associated with nausea and vomiting.[10] Ultrasound and CT scan helps to establish the diagnosis, although it is not uncommon for the diagnosis to be made only at the time of laparotomy.

\section{DISCUSSION OF MANAGEMENT}

Benign lesions account for almost $25 \%$ cases of intussusception in adults. The commonest benign lesion is a lipoma in the colon. These are solitary submucosal lesion with $75 \%$ occurring in the right colon. In our case, we also came across a big submucosal lipoma in the caecum being the lead point for the intussusception. Operative intervention is required in all cases of adult intussusception and unlike children conservative treatment does not work. This usually involves segmental colonic resection. Although, intussusception themselves have a good prognosis, it is often the nature of the lesion causing the intussusception. Mortality for adult intussusception increases from $8.7 \%$ for the benign lesions to $52.4 \%$ for the malignant variety. Our case presented differently that the patient was young. There was no ulceration or bleeding from the tumour surface. It was a sessile tumour with partial lumen obstruction, having a palpable mass, was reducible manually and we succeeded in doing local segmental resection and anastomosis.

\section{FINAL DIAGNOSIS}

Ileo-colocolic intussusception with a submucosal lipoma of caecum as its lead point.

\section{REFERENCES}

[1] Marinis A, Yiallourou A, Samanides L, et al. Intussusception of the bowel in adults: a review. World J Gastroenterol 2009;15(4):407-11.

[2] Ochiai H, Ohishi T, Seki S, et al. Prolapse of intussusception through the anus as a result of sigmoid colon cancer. Case Rep Gastroenterol 2010;4(3):346-50.

[3] Warshauer DM, Lee JK. Adult intussusception detected at CT or MR imaging: clinical-imaging correlation. Radiology 1999;212(3):853-60.

[4] Vyas KC. Lipoma of Intestine. Surgery 1996;1(12):279.

[5] De Moulin D. Paul Barbette, M.D.: a seventeenthcentury Amsterdam author of best-selling textbooks. Bull Hist Med 1985;59(4):506-14.

[6] Bond MR, Roberts JBM. Intussusception in the adults. Brit J Surg 1964;51(11):818-25.

[7] Stubenbord WT, Thorbjarnarson B. Intussusception in adults. Ann of Surgery 1970;172(2):306-10.

[8] Stetten D. The submucus lipoma of the gastro intestinal tract. Surgery Gynec Obstetrics 1909;9:156.

[9] Hackam DJ, Grikschert TC, Wang KS, et al. Pediatric Surgery. In: Schwartz's principles of surgery. Brunicardi FC, Andersen DK, Billiar TR, et al. eds. New York: McGraw-Hill 2010: p. 1433.

[10] Prater JM, Olshemski FC. Adult intussusceptions. Am Fam Physician 1993;47(2):447-52. 